\title{
A Peptidomic Analysis of the Potential Comorbidity Biomarkers for Type 2 Diabetes Mellitus and Alzheimer's Disease
}

\author{
Zhengqiang Du, Jian Hua, Xu Su, Dalin Song* \\ Department of General Medicine, Qingdao Municipal Hospital, Qingdao, China \\ Email: `billy_mei@126.com
}

How to cite this paper: Du, Z.Q., Hua, J., $\mathrm{Su}, \mathrm{X}$. and Song, D.L. (2019) A Peptidomic Analysis of the Potential Comorbidity Biomarkers for Type 2 Diabetes Mellitus and Alzheimer's Disease. Health, 11, 817-826. https://doi.org/10.4236/health.2019.116065

Received: May 9, 2019

Accepted: June 22, 2019

Published: June 25, 2019

Copyright $\odot 2019$ by author(s) and Scientific Research Publishing Inc. This work is licensed under the Creative Commons Attribution International License (CC BY 4.0).

http://creativecommons.org/licenses/by/4.0/

\section{cc) (i) Open Access}

\begin{abstract}
Objective: To investigate the potential comorbidity biomarkers for Type 2 Diabetes Mellitus (T2DM) and Alzheimer's disease (AD). Methods: This is a randomized case-control study. There are three groups: 1) normal control group included 32 healthy elderly people in the hospital physical examination; 2) 30 patients with T2DM group; and 3) AD group has 28 cases. On-line reversed-phase liquid chromatography separation, tandem mass spectrometry analysis and iTRAQ quantification were used for identification of peptidomic analysis, then detection of three comorbidity biomarkers might be associated with T2DM and AD by ELISA. Results: The Peptidomic Analysis of the potential comorbidity biomarkers for T2DM and the AD group includes Osteopontin (OPN), Isoform 2 of Histone H2Btype 2-F and Histone H4. These potential comorbidity biomarkers for T2DM and the $\mathrm{AD}$ group are significantly increased than normal control group. OPN concentrations are 1.67 $(0.13-2.63) \mathrm{mmol} / \mathrm{L}$ in the normal control group, $3.15(1.51-5.35) \mathrm{mmol} / \mathrm{L}$ in the T2DM group, and $7.66(3.55-15.38) \mathrm{mmol} / \mathrm{L}$ in the $\mathrm{AD}$ group. Histone $\mathrm{H} 4$ concentrations in three groups respectively are $0.21 \pm 0.036 \mathrm{mmol} / \mathrm{L}$ (normal control), $0.21 \pm 0.046 \mathrm{mmol} / \mathrm{L}$ (T2DM) and $0.21 \pm 0.034 \mathrm{mmol} / \mathrm{L}(\mathrm{AD})$. Isoforms 2 of Histone H2Btype 2-F are 1.73 (0.12 - 2.60) mmol/L, 4.71 (1.26 6.84) $\mathrm{mmol} / \mathrm{L}$ and $9.30(0-20.8) \mathrm{mmol} / \mathrm{Lin}$ three groups respectively. Conclusion: The inflammatory mechanism may lead to an increase of histone content in the urine of $\mathrm{AD}$ and T2DM patients. Clinical test of these potential comorbidity biomarkers Histones and Osteopontin would be the diagnosis of comorbidity AD and T2DM.
\end{abstract}

\section{Keywords}

Type 2 Diabetes Mellitus (T2DM), Alzheimer's Disease (AD), Comorbidity Biomarkers, Osteopontin, Histones 


\section{Introduction}

Type 2 Diabetes Mellitus (T2DM) and Alzheimer's disease (AD) are consistent in many aspects, which provide a theoretical basis for the correlation between them. There are some mainly manifested in the following aspects that not only highly correlated with the occurrence of T2DM, but also seem to affect the occurrence and development of $\mathrm{AD}: 1$ ) Risk factors: such as genetic factors, advanced age, high-fat diet, obesity and lack of exercise, etc. [1] [2]. 2) Pathogenesis: insulin resistance, toxic effects of high glucose, oxidative stress, inflammatory reaction, hypercholesterolemia, mitochondrial dysfunction [3]-[11]. 3) $\mathrm{Pa}$ thological features: $\mathrm{AD}$ and T2DM patients have specific insoluble polymer deposition in their bodies. Amyloid $\beta$-protein $(\mathrm{A} \beta)$ deposits were found in the brain of patients with $\mathrm{AD}$, and abnormal deposition of $\mathrm{A} \beta$ was found in islet beta cells of patients with $\mathrm{T} 2 \mathrm{DM}$, suggesting that $\mathrm{A} \beta$ was formed by unnatural folding and aggregation of the homologous protein-Islet amyloid polypeptide (IAPP) [12] [13]. 4) Treatment: long-acting insulin analogues (LAIA) of Glucagon-like peptide-1 (GLP-1) have been widely used in clinical practice as a novel drug for the treatment of T2DM. In recent years, GLP-1 and its analogues have been proved to improve the cognitive function of $\mathrm{AD}$ model mice [14]. So far, there are no studies to reveal potential comorbidity biomarkers for T2DM and AD. This research was used to analyze peptides spectrum of the urine within T2DM and $\mathrm{AD}$ patients by Mass Spectrometry, as well as explore the mechanism of comorbidity.

\section{Materials and Methods}

\subsection{Objectors}

This is a randomized case-control study, and has been approved by the hospital ethics committee since 2015. All sample s signed the informed consent and are divided into three groups: 1) normal control group included 32 healthy elderly people in the hospital physical examination; 2) 30 patients with T2DM group; and 3) AD group has 28 cases. All patients are admitted to the Geriatric department of Qingdao municipal hospital. Exclusion criteria: hypertension, coronary heart disease, stroke, cerebrovascular disease, head trauma, Parkinson's syndrome. The patients in T2DM group had no cognitive impairment or depression T2DM group complication, as well as AD patients have been clearly diagnosed without diabetes mellitus.

\subsection{Sample Preparation}

The venous plasma and urine samples are collected in the morning when all subjects were on an empty stomach. Using sterilized bottles with $5-10 \mathrm{ml}$ urine, the samples are stored in the $-80^{\circ} \mathrm{C}$ refrigerator within two hours for later use. Enrichment of peptides in the urine of 1) will be saved out of A healthy person's urine specimen, thaw at room temperature, in $4^{\circ} \mathrm{C}$, under the condition of 12,000 RPM centrifuge for 10 min after absorbing supernatant in another clean 
EP tube, notes for A; 2) add the aqueous dispersion of lanthanum-grapheme magnetic material into $A$ at the ratio of urine:material $=50: 1$, and vortex at 2000 $\mathrm{rmp} / \mathrm{min}$ for $10 \mathrm{~min}$; Centrifuge at $1000 \mathrm{rpm}$ for $5 \mathrm{~min}$, and take the precipitate, denoted as B; 3) $500 \mu \mathrm{l}$ water was added to $\mathrm{B}$, vortex at $1000 \mathrm{rmp} / \mathrm{min}$ for 10 min, centrifuge at $1000 \mathrm{rpm}$ for $5 \mathrm{~min}$, and the supernatant was discarded from the obtained samples. The corresponding precipitation was repeated for 2 times, and the final sample was recorded as C; 4) add $20 \mu$ eluent to C, vortex at 2000 $\mathrm{rmp} / \mathrm{min}$ for $10 \mathrm{~min}$, centrifuge at $1000 \mathrm{rpm}$ for $10 \mathrm{~min}$, and transfer the supernatant to another EP tube, denoted as D; 5) centrifuge D at 12,000 rpm for 10 min, discard supernatant, seal with sealing film, bind a considerable number of holes in the sealing film, and freeze dry the specimen in vacuum freeze-dryer, denoted as E.

\subsection{On-Line Reversed-Phase Liquid Chromatography Separation and Tandem Mass Spectrometry Analysis}

Equipment and materials: Centrifuge; Oscillator; Aqueous dispersion of lanthanum-grapheme magnetic materials: $(30 \mathrm{mg} / \mathrm{ml})$; Vacuum freeze dryer; Eluent: $80 \% \mathrm{ACN}$ containing $1 \% \mathrm{TFA}$; Liquid chromatography liquid A ( $0.1 \%$ formic ac$\mathrm{id} / 2 \%$ acetonitrile/98\% aqueous solution); B solution ( $0.1 \%$ formic acid/2\% water/98\% acetonitrile solution); Analysis column: $75 \mathrm{~m} \times 15 \mathrm{~cm}, \mathrm{c} 18-3 \mathrm{~m} 120 \mathrm{~A}$; Column: 3 m, 120 A; EksigentnanoLC-Ultra ${ }^{\text {tw }} 2$ d performance liquid chromatography (HPLC)-TripleTOF 5600 mass spectrometry instrument; OLYMPUS au1000/2700 automatic biochemical analyzer.

Sample E was dissolved in a solution of $0.1 \%$ formic acid/2\% acetonitrile/98\%. The sample was loaded at about $2 \mu \mathrm{g}$ on the Nano liter flow column, desalted in liquid A for $10 \mathrm{~min}$, then elution was carried out in liquid B, and the sample was scanned by mass spectrometry.

\subsection{Database Search and iTRAQ Quantification}

The raw peptides, protein identification and quantification were performed using ProteinPilot v4.5 (AB Sciex) with the Paragon Algorithm against the UniProt "complete proteome" human proteins database. To reduce false positive identification results, a minimum unused score of 1.3 (equivalent to $95 \%$ confidence) and false discovery rate (FDR) less than $1 \%$ were required for all reported proteins. At least one unique peptide per protein group was required for identification of proteins, while two quantified peptides were required for quantification of proteins. Based on a 95\% confidence level, cutoff values of 1.5-fold for unregulated proteins and of 0.67 -fold for downregulated proteins were used to identify differentially expressed proteins between the patients and healthy controls [15].

\subsection{Detection of Three Comorbidity Biomarkers Might Be Associated with T2DM and AD by ELISA}

The decrease levels of osteopontin (OPN) and Histone $\mathrm{H} 4$ were detected in the 
serum of T2DM and AD patients compared with that of healthy controls. OPN ELISA kit is R\&D Systems, and Human Histone H4 and Histone H2B type 2 ELISA kits are Cusabio.

\subsection{Statistical Calculation}

PASW Statistics 18 software was used to establish database and statistical analysis; mean standard deviation was used for parameter continuous variables; $t$ test was used for two groups; Nonparametric continuous variables were expressed as median (minimum - maximum), and paired q test was used for the two groups. Variance analysis was used to compare continuous variables among groups. The rate comparison was conducted by Fisher's exact test. P $<0.05$ was considered statistically significant.

\section{Results}

\subsection{Basic Clinical Parameter}

There were significant differences in blood glucose levels between the T2DM group and the control group, and between the T2DM group and the AD group $(P=0.017)$. There was no statistically significant difference in blood glucose levels between the control group and the $\mathrm{AD}$ group (Table 1).

\subsection{The Peptidomic Analysis of the Potential Comorbidity Biomarker}

816 polypeptides corresponding to 100 proteins were detected in the urine of patients with T2DM. We were successfully identified, out of which 279 and 386 serum proteins were identified in $\mathrm{AD}$. A total of 1048 peptides corresponding to 133 proteins were detected in normal urine. The contents and types of polypeptides in urine of the two groups were different, and the corresponding proteins were also different. Table 2 shows the protein types and amounts corresponding to the top 10 peptides in urine of the three groups. The Peptidomic Analysis of the potential comorbidity biomarkers for T2DM and the $\mathrm{AD}$ group include: Osteopontin, Isoform 2 of Histone H2Btype 2-F and Histone H4 (Table 2 and Figure 1 and Figure 2).

\subsection{Comparison of These Potential Comorbidity Biomarkers for among Three Groups}

OPN concentration are $1.67(0.13-2.63) \mathrm{mmol} / \mathrm{L}$ in the normal control group, $3.15(1.51-5.35) \mathrm{mmol} / \mathrm{L}$ in the T2DM group, and 7.66 (3.55 - 15.38) $\mathrm{mmol} / \mathrm{L}$ in the $\mathrm{AD}$ group. Histone $\mathrm{H} 4$ concentration in three groups respectively are $0.21 \pm$ $0.036 \mathrm{mmol} / \mathrm{L}$ (normal control), $0.21 \pm 0.046 \mathrm{mmol} / \mathrm{L}(\mathrm{T} 2 \mathrm{DM})$ and $0.21 \pm 0.034$ $\mathrm{mmol} / \mathrm{L}(\mathrm{AD})$. Isoform 2 of Histone H2Btype 2-F are 1.73 (0.12 - 2.60) $\mathrm{mmol} / \mathrm{L}$, $4.71(1.26$ - 6.84) $\mathrm{mmol} / \mathrm{L}$ and $9.30(0-20.8) \mathrm{mmol} / \mathrm{Lin}$ three groups respectively. These potential comorbidity biomarkers for T2DM and the AD group are significantly increased than normal control group (Figure 3). 


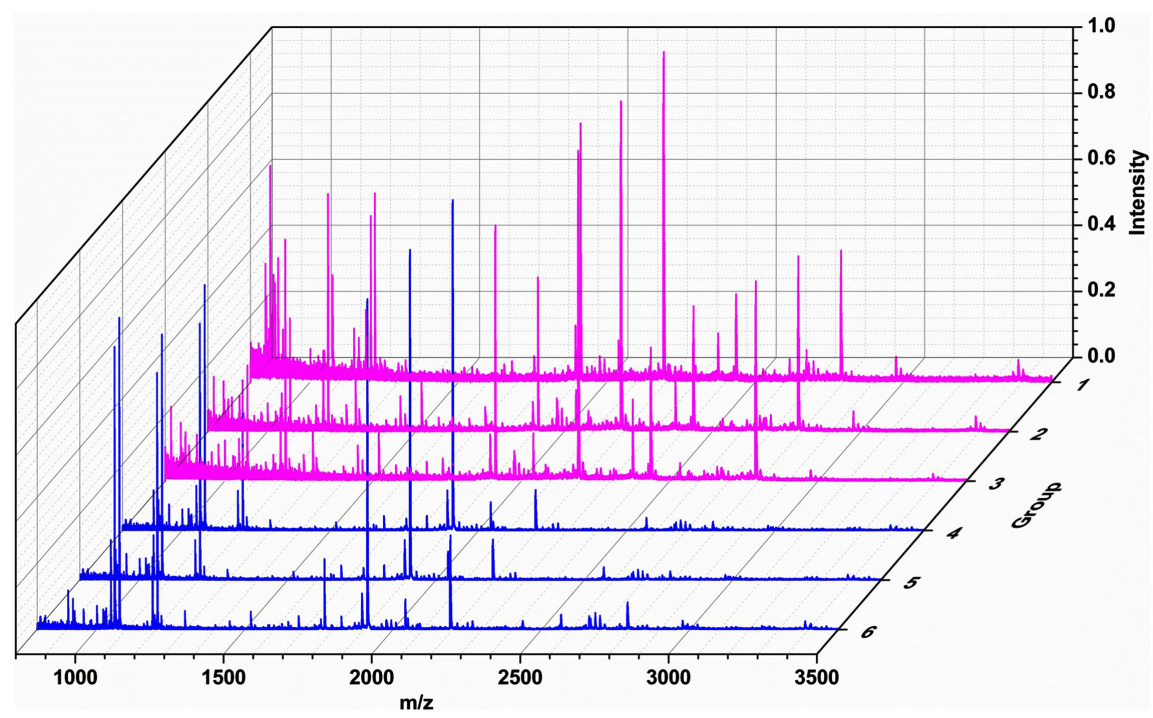

Figure 1. Urine sample markers of the polypeptide group detection by mass spectrometry.

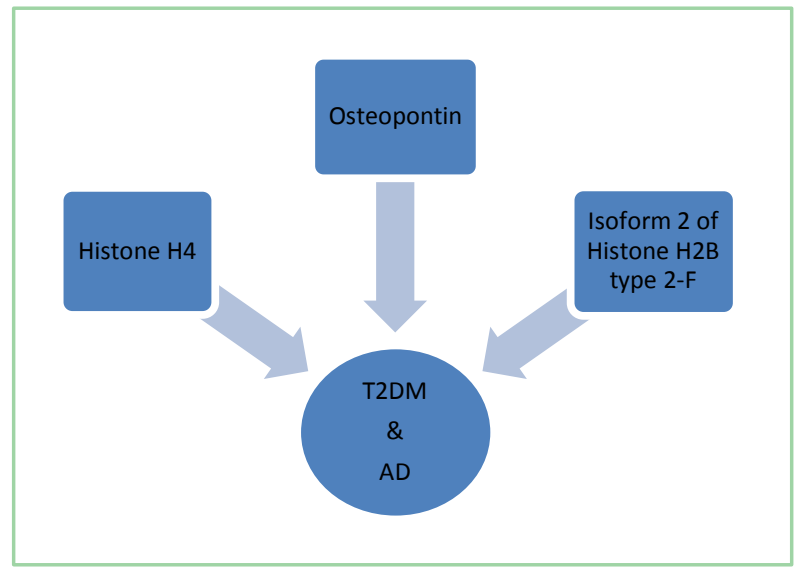

Figure 2. The peptidomic analysis of the potential comorbidity biomarkers for T2DM and the $\mathrm{AD}$ group.
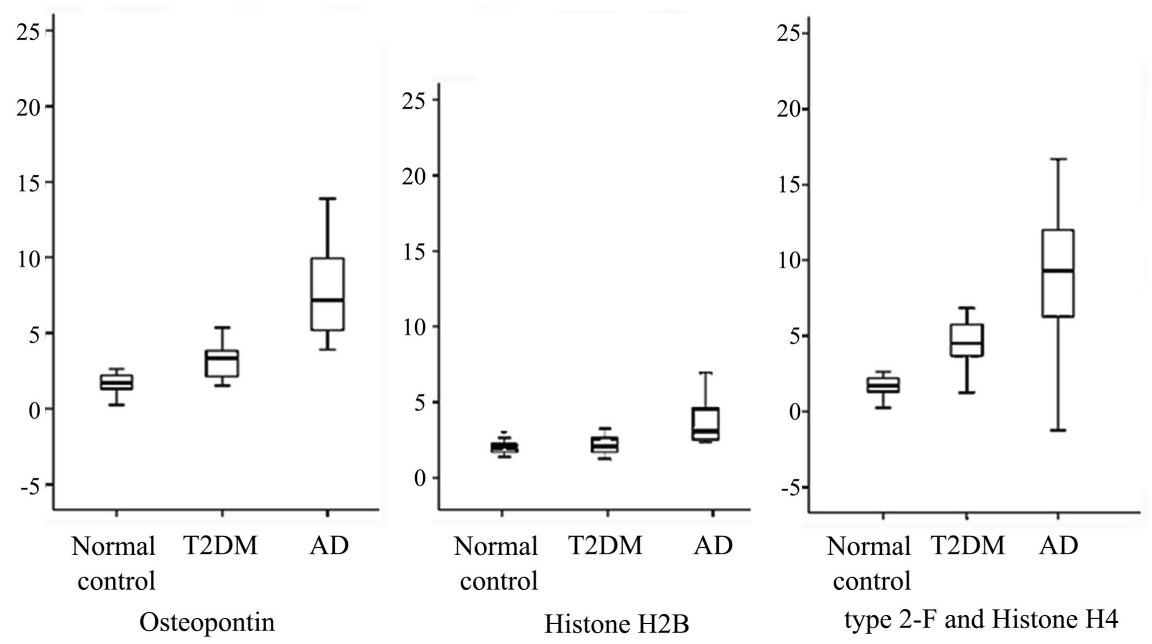

Figure 3. Comparison of these potential comorbidity biomarkers for among three groups. 
Table 1. Comparison of clinical parameters among the three groups.

\begin{tabular}{cccccc}
\hline $\begin{array}{c}\text { Clinical } \\
\text { parameters }\end{array}$ & $\begin{array}{c}\text { Normal control } \\
(\mathrm{n}=32)\end{array}$ & $\begin{array}{c}\text { T2DM } \\
(\mathrm{n}=30)\end{array}$ & $\begin{array}{c}\mathrm{AD} \\
(\mathrm{n}=28)\end{array}$ & $F / H$ & $\mathrm{P}$ \\
\hline Age $(\bar{x} \pm s, y)$ & $70.14 \pm 14.14$ & $71.90 \pm 7.12$ & $71.20 \pm 8.35$ & 2.11 & $>0.05$ \\
$\mathrm{M} / \mathrm{F}(\mathrm{case})$ & $17 / 15$ & $18 / 12$ & $15 / 13$ & 1.05 & $>0.05$ \\
$\mathrm{BMI}\left(\mathrm{kg} / \mathrm{m}^{2}\right)$ & $24.00(19.9-28.1)$ & $24.85(21.3-28.4)$ & $23.5(19.0-28.0)$ & 1.21 & $>0.05$ \\
$\mathrm{SBP}(\mathrm{mmHg})$ & $131(122-140)$ & $136(122-150)$ & $131(120-142)$ & 0.24 & $>0.05$ \\
$\mathrm{DBP}(\mathrm{mmHg})$ & $77.5(65-90)$ & $80.0(65-95)$ & $79.0(63-95)$ & 0.67 & $>0.05$ \\
$\mathrm{TG}(\mathrm{mmol} / \mathrm{L})$ & $1.34 \pm 0.87$ & $1.87 \pm 0.38$ & $1.40 \pm 0.74$ & 1.82 & $>0.05$ \\
$\mathrm{HDL}(\mathrm{mmol} / \mathrm{L})$ & $1.35 \pm 0.07$ & $1.21 \pm 0.06$ & $1.16 \pm 0.08$ & 1.66 & $>0.05$ \\
$\mathrm{LDL}(\mathrm{mmol} / \mathrm{L})$ & $4.03 \pm 0.69$ & $3.62 \pm 0.82$ & $4.12 \pm 0.65$ & 2.45 & $>0.05$ \\
$\mathrm{FPG}(\mathrm{mmol} / \mathrm{L})$ & $5.97 \pm 0.73$ & $8.9 \pm 0.79$ & $6.57 \pm 0.81$ & 7.08 & $<0.05^{\star}$ \\
\hline
\end{tabular}

F/H: Fisher's exact test/H.

Table 2. Top 10 peptides in urine of three groups.

\begin{tabular}{|c|c|c|c|}
\hline No & Normal control & $\mathrm{T} 2 \mathrm{DM}$ & $\mathrm{AD}$ \\
\hline 1 & Alpha-1-antitrypsin & Alpha-1-antitrypsin & $\begin{array}{l}\text { Isoform } 2 \text { of Histone } \mathrm{H} 2 \mathrm{~B} \text { type } \\
2-\mathrm{F}\end{array}$ \\
\hline 2 & $\begin{array}{l}\text { Leucine-rich } \\
\text { alpha-2-glycoprotein }\end{array}$ & Transthyretin & Actin \\
\hline 3 & Hemoglobin subunit beta & Hemoglobin subunit alpha & Osteopontin \\
\hline 4 & Angiotensinogen & Hemoglobin subunit $\beta$ & $\begin{array}{l}\text { Human Inter-alpha-trypsin } \\
\text { inhibitor heavy chain H4 } \\
\text { (ITIH4) }\end{array}$ \\
\hline 5 & Plasma protease $\mathrm{C} 1$ inhibitor & Apolipoprotein A-I & Histone $\mathrm{H} 4$ \\
\hline 6 & Hemoglobin subunit alpha & Osteopontin & Histone $\mathrm{H} 2 \mathrm{~A}$ \\
\hline 7 & HP protein & Apolipoprotein A-IV & $\beta-2$ microglobulin, \\
\hline 8 & Carbonic anhydrase 1 & Complement C3 & $\begin{array}{l}\text { Glyceraldehyde-3-phosphate } \\
\text { dehydrogenase (GAPD) }\end{array}$ \\
\hline 9 & Uromodulin & $\begin{array}{l}\text { Isoform } 2 \text { of Histone } \mathrm{H} 2 \mathrm{~B} \\
\text { type } 2-\mathrm{F}\end{array}$ & Ceruloplasmin (CER) \\
\hline 10 & $\begin{array}{l}\text { Isoform } 2 \text { of Prostatic acid } \\
\text { phosphatase }\end{array}$ & Histone $\mathrm{H} 4$ & trypsin inhibitor $\mathrm{H} 4$ \\
\hline
\end{tabular}

\section{Discussion}

These results demonstrate that Histones and Osteopontin may be involved in the pathogenesis of $\mathrm{AD}$ patients and $\mathrm{T} 2 \mathrm{DM}$ patients, and the inflammatory mechanism may lead to the increase of histone content in the urine of $A D$ and T2DM patients. Clinical test of these potential comorbidity biomarkers would be the diagnosis of comorbidity $\mathrm{AD}$ and $\mathrm{T} 2 \mathrm{DM}$.

There are 5 subtypes of histones, namely histone $\mathrm{H} 1$, histone $\mathrm{H} 2 \mathrm{~A}$, histone $\mathrm{H} 2 \mathrm{~B}$, histone $\mathrm{H} 3$ and histone $\mathrm{H} 4$. In this experiment, the contents of histone 
$\mathrm{H} 2 \mathrm{~B}$, histone $\mathrm{H} 2 \mathrm{~A}$ and histone $\mathrm{H} 4$ in the urine of $\mathrm{AD}$ patients and T2DM patients were significantly increased. The main role of histones is to participate in the formation of nucleosomes and maintain the stability of chromosome structure. However, the role of histones is increasingly recognized with the development of research with developing research. Silva et al. [16] revealed that histones are closely related to learning and memory. This study showed that the acetylation of histones can activate the transcription of genes related to learning and memory formation, increase the formation of synapses, and thus promote the process of learning and memory. Histone acetylation is regulated by both acetylase and deacetylase. Studies have shown that the expression of histone deacetylases (HDACs) in the brain of patients with $\mathrm{AD}$ is increased, and the level of white acetylases in group b is decreased [17]. On the other hand, HDAC6 in the cytoplasmic nucleus could regulate the phosphorylation process of Tau protein by interacting, and further form fiber tangles to participate in the pathogenesis of $\mathrm{AD}$ [18]. In addition, histones are also involved in inflammatory reactions through the nl-rp3 pathway, and inflammatory cytokines are released and neutrophils are recruited [19]. Friggeri et al. [20] confirmed that both histone H3 and $\mathrm{H} 4$ could weaken the uptake and clearance of mononuclear phagocytes to apoptotic cells in vivo and in vitro experiments, thus enhancing the inflammatory response. Pemberton et al. [21] found that histone can make low-density lipoprotein deposit in the blood vessels, which may be the early change of atherosclerosis. This finding may provide a new way to explain vascular diseases in DM patients.

Some experiments aimed at exploring whether OPN was related to T2DM complications. Genomics studies have shown that increased OPN level in different diabetic nephropathy models is closely related to severe DN proteinuria [22]. Another study pointed out that plasma OPN level was positively correlated with DN, and no evidence was found that plasma OPN level was correlated with DM retinopathy and neuropathy [23]. Transient proteinuria was observed in 6 weeks old male mice $24 \mathrm{~h}$ after LPS injection. After dissection, kidney lysates were taken from the mice in this group, and quantitative real-time PCR analysis showed that the level of OPN mRNA was significantly increased. For answer the question of whether OPN plays a role in the development of proteinuria, the researchers treated mice with gene knockout technology and found that no significant proteinuria was found in the OPN gene knockout mice 24 hours after the injection of bacterial LPS compared with the wild-type mice. Thus, it was speculated that OPN was involved in the formation of proteinuria [24]. Later, Nicholas et al. [25] showed that the excretion rate of urinary protein in OPN gene knockout mice decreased significantly.

As 6-month-old APP/PS1KI model mice have axonal degeneration, neuron loss and memory loss, they are often used in relevant studies on AD. Some data demonstrated that the OPN in the brain of 6-month-old APP/PS1KI model mice was 2.8 times that of 2 -month-old mice $(\mathrm{P}=0.01)$, and the immunohistochemical staining with the anti-mouse OPN antibody showed enhanced brain reactiv- 
ity. After staining with A and OPN double antibodies, it was found that the mouse axon antibody was significantly deposited [26]. Clinical studies have shown that the content of OPN in cerebrospinal fluid of AD patients is higher than that of mild cognitive impairment (MCI). This study points out that OPN could be used as an indicator to predict whether MCI patients progress to $\mathrm{AD}$ [27].

At present, the levels of histone and OPN in AD patients are still controversial at home and abroad, and the specific mechanism is conversely being explored. Our study has several limitations. First, the small sample size prevented us from extrapolating the results to all T2DM populations. Secondly, patients with MCI were not included, and relevant data of such population were lacking. Finally, the inclusive statistics did not include glycosylated hemoglobin, which could not well reflect the effect of blood glucose fluctuations on the test results. Therefore, it is reasonable to increase the sample size and different categories, and improve the extensive examination indicators (such as $\mathrm{HbAlc}$ ).

\section{Conflicts of Interest}

The authors declare no conflicts of interest regarding the publication of this paper.

\section{References}

[1] Gtz, J., Ittner, L.M. and Lim, Y.A. (2009) Common Features between Diabetes Mellitus and Alzheimer's Disease. Cellular and Molecular Life Sciences, 66, 1321-1325. https://doi.org/10.1007/s00018-009-9070-1

[2] Jin, W. and Patti, M.E. (2009) Genetic Determinants and Molecular Pathways in the Pathogenesis of Type 2 Diabetes. Clinical Science, 116, 99-111. https://doi.org/10.1042/CS20080090

[3] Paolisso, G. and Giugliano, D. (1996) Oxidative Stress and Insulin Action: Is There a Relationship? Diabetologia, 39, 357-363. https://doi.org/10.1007/s001250050454

[4] Beydoun, M.A., Lhotsky, A., Wang, Y., Dal Forno, G., An, Y., Metter, E.J., Ferrucci, L., O’Brien, R. and Zonderman, A.B. (2008) Association of Adiposity Status and Changes in Early to Mid-Adulthood with Incidence of Alzheimer's Disease. American Journal of Epidemiology, 168, 1179-1189. https://doi.org/10.1093/aje/kwn229

[5] Dela Monte, S.M. and Wands, J.R. (2008) Alzheimer's Disease Is Type 3 Diabetes-Evidence Reviewed. Journal of Diabetes Science and Technology, 2, 1101-1113. https://doi.org/10.1177/193229680800200619

[6] Qiu, W.Q. and Folstein, M.F. (2006) Insulin, Insulin-Degrading Enzyme and Amyloid-Beta Peptide in Alzheimer's Disease: Review and Hypothesis. Neurobiology of Aging, 27, 190-198. https://doi.org/10.1016/j.neurobiolaging.2005.01.004

[7] Hotamisligi, G.S. (2007) Inflammation and Metabolic Disorders. Nature, 444, 860-867. https://doi.org/10.1038/nature05485

[8] Mcgeer, P.L., Rogers, J. and Mcgeer, E.G. (1994) Neuroimmune Mechanisms in Alzheimer Disease Pathogenesis. Alzheimer Disease \& Associated Disorders, 8, 149-158. https://doi.org/10.1097/00002093-199408030-00001

[9] Reddy, P.H., Tripathi, R., Troung, Q., Tirumala, K., Reddy, T.P., Anekonda, V., Shirendeb, U.P., Calkins, M.J., Reddy, A.P., Mao, P. and Manczak, M. (2012) Ab- 
normal Mitochondrial Dynamics and Synaptic Degeneration as Early Events in Alzheimer's Disease: Implications to Mitochondria-Targeted Antioxidant Therapeutics. Biochimica et Biophysica Acta, 1822, 639-649.

https://doi.org/10.1016/j.bbadis.2011.10.011

[10] Verdelho, A., Madureira, S., Moleiro, C., et al. (2010) White Matter Changes and Diabetes Predict Cognitive Decline in the Elderly: The LADIS Study. Neurology, 75, 160-167. https://doi.org/10.1212/WNL.0b013e3181e7ca05

[11] Kawarabayashi, T., Shoji, M., Younkin, L.H., et al. (2004) Dimeric Amyloid Beta Protein Rapidly Accumulates in Lipid Rafts Followed by Apolipoprotein E and Phosphorylated Tau Accumulation in the Tg2576 Mouse Model of Alzheimer's Disease. Journal of Neuroscience, 24, 3801-3809.

https://doi.org/10.1523/JNEUROSCI.5543-03.2004

[12] Yan, L.M., Velkova, A., Tatarek-Nossol, M., et al. (2007) IAPP Mimic Blocks A Beta Cytotoxic Self-Assembly: Cross-Suppression of Amyloid Toxicity of A Beta and IAPP Suggests a Molecular Link between Alzheimer's Disease and Type II Diabetes. Angewandte Chemie International Edition, 46, 1246-1252. https://doi.org/10.1002/anie.200604056

[13] Kahn, S.E., Andrikopoulos, S. and Verchere, C.B. (1999) Islet Amyloid: A Long-Recognized But Underappreciated Pathological Feature of Type 2 Diabetes. Diabetes, 48, 241-253. https://doi.org/10.2337/diabetes.48.2.241

[14] Abbas, T., Faivre, E. and Hlscher, C. (2009) Impairment of Synaptic Plasticity and Memory Formation in GLP-1 Receptor KO Mice: Interaction between Type 2 Diabetes and Alzheimer's Disease. Behavioural Brain Research, 205, 265-271. https://doi.org/10.1016/j.bbr.2009.06.035

[15] Wang, J., Yao, L., Li, B., Meng, Y., Ma, X., Lai, Y., Si, E., Ren, P., Yang, K., Shang, X. and Wang, H. (2016) Comparative Proteomic Analysis of Cultured Suspension Cells of the Halophyte Halogetonglomeratus by iTRAQ Provides Insights into Response Mechanisms to Salt Stress. Frontiers in Plant Science, 7, 110. https://doi.org/10.3389/fpls.2016.00110

[16] Silva, P.F., Garcia, V.A., Domelles Ada, S., et al. (2012) Memory Impairment Induced by Brain Iron Overload Is Accompanied by Reduced H3K9 Acetylation and Ameliorated by Sodium Butyrate. Neuroscience, 200, 42-49. https://doi.org/10.1016/j.neuroscience.2011.10.038

[17] Fischer, A., Sananbenesi, F., Mungenast, A., et al. (2010) Targeting the Correct HDAC(s) to Treat Cognitive Disorders. Trends in Pharmacological Sciences, 31, 605-617. https://doi.org/10.1016/j.tips.2010.09.003

[18] Perez, M., Santa-Maria, I., Gomez de Barreda, E., et al. (2009) Tau-An Inhibitor of Deacetylase HDAC6 Function. Journal of Neurochemistry, 109, 1755-1766. https://doi.org/10.1111/j.1471-4159.2009.06102.x

[19] Huang, H., Chen, H.W., Evankovich, J., et al. (2013) Histones Activate the NLRP3 Inflammasome in Kupffer Cells during Sterile Inflammatory Liver Injury. The Journal of Immunology, 191, 2665-2679. https://doi.org/10.4049/jimmunol.1202733

[20] Friggeri, A., Banerjee, S., Xie, N., et al. (2012) Extracellular Histones Inhibit Efferocytosis. Molecular Medicine, 18, 825-833. https://doi.org/10.2119/molmed.2012.00005

[21] Pemberton, A.D. and Brown, J.K. (2010) In Vitro Interactions of Extracellular Histones with LDL Suggest a Potential Proatherogenic Role. PLoS ONE, 5, e9884. https://doi.org/10.1371/journal.pone.0009884

[22] Susztak, K., Bottinger, E., Novetsky, A., et al. (2004) Molecular Profiling of Diabetic 
Mouse Kidney Reveals Novel Genes Linked to Glomerular Disease. Diabetes, 53, 784-794. https://doi.org/10.2337/diabetes.53.3.784

[23] Yamaguehi, H., Igarashi, M., Hirata, A., et al. (2004) Progression of Diabetic Nephropathy Enhances the Plasma Osteopontin Level in Type 2 Diabetic Patients. Endocrine Journal, 51, 499. https://doi.org/10.1507/endocrj.51.499

[24] Lorenzen, J., Shah, R., Biser, A., et al. (2008) The Role of Osteopontin in the Development of Albuminuria. Journal of the American Society of Nephrology, 19, 884-890. https://doi.org/10.1681/ASN.2007040486

[25] Nicholas, S.B., Liu, J., Kim, J., et al. (2010) Critical Role for Osteopontin in Diabetic Nephrnpathy. Kidney International, 77, 588-600. https://doi.org/10.1038/ki.2009.518

[26] Wirths, O., Breyhan, H., Marcello, A., et al. (2010) Inflammatory Changes Are Tightly Associated with Neurodegeneration in the Brain and Spinal Cord of the APP/PS1KI Mouse Model of Alzheimer's Disease. Neurobiology of Aging, 31, 747-757. https://doi.org/10.1016/j.neurobiolaging.2008.06.011

[27] Simonsen, A.H., Mcguire, J., Hansson, O., et al. (2007) Novel Panel of Cerebrospinal Fluid Biomarkers for the Prediction of Progression to Alzheimer Dementia in $\mathrm{Pa}$ tients with Mild Cognitive Impairment. Archives of Neurology, 64, 366-370.

https://doi.org/10.1001/archneur.64.3.366 